\title{
Scalable transient gene expression in Chinese hamster ovary cells in instrumented and non-instrumented cultivation systems
}

\author{
Natalie Muller · Madiha Derouazi · Frédéric Van Tilborgh · Sarah Wulhfard · \\ David L. Hacker · Martin Jordan · Florian M. Wurm
}

Received: 22 November 2006/Revised: 15 December 2006/ Accepted: 16 December 2006/

Published online: 20 February 2007

(C) Springer Science+Business Media B.V. 2007

\begin{abstract}
Cell expansion, gene transfer and protein production were all executed with a single serum-free, animal protein-free commercial medium designed for suspension-adapted Chinese hamster ovary cells (CHO DG44). This is a most important process to consider for clinical production of recombinant proteins. The transfection with polyethylenimine (PEI) was shown here to be scalable using both stirred-tank bioreactors of
\end{abstract}

N. Muller · M. Derouazi · F. Van Tilborgh .

S. Wulhfard · D. L. Hacker · M. Jordan .

F. M. Wurm ( $\square)$

École Polytechnique Fédérale de Lausanne (EPFL),

Institute of Bioengineering, Laboratory of Cellular

Biotechnology, 1015 Lausanne, Switzerland

e-mail: florian.wurm@epfl.ch

Present Address:

M. Derouazi

Department of Biological Haematology, CHU de GRENOBLE, BP217, 38043 Grenoble Cedex 9, France

Present Address:

F. Van Tilborgh

Apoxis S.A., 18 av. de Sévelin, 1004 Lausanne,

Switzerland

Present Address:

M. Jordan

Laboratoires Serono SA - Succursale de Corsier-sur-

Vevey, Route de Fenil Z.I. B, 1804 Corsier-sur-

Vevey, Switzerland
3- and 150-1 and novel agitated cultivation vessels (50 ml ventilated centrifuge tubes and 1-1 squareshaped glass bottles) that lack any instrumentation. The transient transfections spanned a range of working volumes from $2 \mathrm{ml}$ to $80 \mathrm{l}$. The maximum transient recombinant antibody yield was $22 \mathrm{mg} / \mathrm{l}$, the highest ever reported for a multiliter transfection in $\mathrm{CHO}$. The transiently expressed protein had the same extent of glycosylation as the same antibody produced from a stably transfected recombinant $\mathrm{CHO}$ cell line.

Keywords Antibody · Bioreactor · Orbital shaker · Polyethylenimine - Recombinant protein $\cdot$ Suspension cells

\section{Introduction}

Using low cost DNA delivery agents, such as calcium phosphate (Jordan et al. 1996) and polyethylenimine (PEI) (Boussif et al. 1995), suspension cultures of mammalian cells at volumes up to 1001 have been transfected for the transient production of recombinant proteins. The two major hosts for these processes are human embryo kidney (HEK 293) and Chinese hamster ovary (CHO) cells with the volumetric yields of secreted recombinant proteins being higher with HEK 293 cells (Schlaeger and Christensen 1999; Meissner et al. 2001; Girard et al. 2002; Pham 
et al. 2003; Schlaeger et al. 2003; Derouazi et al. 2004; Tait et al. 2004; Pham et al. 2005; Rosser et al. 2005; Baldi et al. 2005; Galbraith et al. 2006). Transient gene expression has been performed in several non-instrumented cultivation systems including multiwell plates (Girard et al. 2001; Derouazi et al. 2004), spinner flasks (Schlaeger and Christensen 1999; Meissner et al. 2001; Rosser et al. 2005; Baldi et al. 2005), and shake-flasks (Tait et al. 2004; Rosser et al. 2005) as well as in stirred-tank bioreactors (Girard et al. 2002; Derouazi et al. 2004).

For regulatory reasons, it is necessary to transiently express recombinant proteins destined for therapeutic applications in chemically defined conditions without animal-derived components such as serum. The elimination of these components reduces the risk of contamination of the recombinant protein with infectious agents. The elimination of serum in particular facilitates the purification of secreted recombinant proteins and reduces the cost and variability of the production process. These restrictions, however, may limit the scope of transient gene expression technology. The absence of serum, for example, substantially reduces the efficiency of calcium phosphate-mediated transfection (Jordan et al. 1996). PEI-mediated DNA transfer, on the other hand, is serum-independent (Pham et al. 2003; Derouazi et al. 2004; Tait et al. 2004; Rosser et al. 2005), and it can be performed in minimal media or in complex media formulated for serum-free suspension cultures (Derouazi et al. 2004; Tait et al. 2004; Rosser et al. 2005).

Here we report the PEI-mediated transfection of $\mathrm{CHO}$ cells in a medium formulated for highdensity suspension growth of this cell line in the absence of animal-derived components. The method was shown to be scalable over a broad range of working volumes using both non-instrumented and instrumented cultivation systems that included two novel shaken vessels, 50-ml ventilated centrifuge tubes and 1-1 square-shaped glass bottles, which have previously been shown to support growth of $\mathrm{CHO}$ cells to high densities (De Jesus et al. 2004; Muller et al. 2005). The development of a scalable transient gene expression method for $\mathrm{CHO}$ cells using a single medium for both cell cultivation and transfection is expected to facilitate the transient production of recombinant proteins in this cell line.

\section{Materials and methods}

Cell culture

Suspension-adapted CHO DG44 cells (a dihydrofolate reductase deficient mutant) were routinely cultivated in 1-1 square-shaped glass bottles (Schott Glass, Mainz, Germany) in ProCHO5 CDM medium (Cambrex, East Rutherford, NJ) supplemented with $4 \mathrm{mM}$ glutamine, $0.68 \mathrm{mg}$ hypoxanthine/l, and $0.194 \mathrm{mg}$ thymidine (GHT)/l as previously described (Muller et al. 2005). One day prior to transfection, unless otherwise stated, the cells were transferred in to $400 \mathrm{ml}$ fresh ProCHO5 CDM medium with GHT to give $1 \times 10^{6}$ cells $/ \mathrm{ml}$. The packed cell volume $(\mathrm{PCV})$ was determined using mini-PCV tubes (TPP, Trasadingen, Switzerland) as previously described (Stettler et al. 2006).

Plasmids

pEAK8-LH39 and pEAK8-LH41 carrying the full-length cDNAs of the anti-Rhesus D light and heavy chain IgG genes, respectively, were described previously (Pick et al. 2002). pEAK8 was purchased from Edge Biosystems (Gaithersburg, MD). pEGFP-N1 was purchased from Clontech (Palo Alto, CA). Plasmid DNA was purified on a Nucleobond AX anion exchange column (Macherey-Nagel, Düren, Germany) according to the manufacturer's protocol.

\section{Transfection}

Linear $25 \mathrm{kDa}$ PEI (pH 7.0) (Polysciences, Eppenheim, Germany) was prepared in water at $1 \mathrm{mg} / \mathrm{ml}$ and sterilized by filtration. For each $\mathrm{ml}$ of culture, $2.5 \mu \mathrm{g}$ DNA and varying amounts of PEI were added separately to $50 \mu \mathrm{l} 150 \mathrm{mM}$ $\mathrm{NaCl}$. Prior to addition to the culture, the PEI solution was added to the DNA solution and allowed to stand at room temperature for $10 \mathrm{~min}$ (Derouazi et al. 2004). Unless otherwise indicated, the transfections were performed with a 
mixture of pEAK8-LH41, pEAK-LH39, and pEGFP-N1 at 68:30:2 (by wt) for optimal expression of $\mathrm{IgG}$ and GFP as described previously (Pick et al. 2002).

For transfections in 12-well plates, the cells were centrifuged and resuspended in either RPMI 1640 (Applichem, Darmstadt, Germany) containing $25 \mathrm{mM}$ HEPES ( $\mathrm{pH}$ 7.1) or ProCHO5 CDM with GHT. Aliquots of $1 \mathrm{ml}$ were then distributed at a density of $1-2 \times 10^{6}$ cells $/ \mathrm{ml}$ into 12 -well plates. After transfection the cultures were incubated at $37^{\circ} \mathrm{C}$ in $5 \% \mathrm{CO}_{2}$ with $90 \%$ humidity with agitation on an orbital shaker at $180 \mathrm{rpm}$ (Girard et al. 2001). After $4 \mathrm{~h}$, one volume of medium was added to each well.

For transfections in $50 \mathrm{ml}$ ventilated centrifuge tubes (TPP) (De Jesus et al. 2004), the cells were centrifuged and resuspended in ProCHO5 CDM with GHT. Aliquots of $5 \mathrm{ml}$ were added to each $50 \mathrm{ml}$ tube at $2 \times 10^{6}$ cells $/ \mathrm{ml}$. Following DNA addition, the tubes were shaken at $140 \mathrm{rpm}$ at $37^{\circ} \mathrm{C}$ in $5 \% \mathrm{CO}_{2}$ with $85 \%$ humidity. After $4 \mathrm{~h}$, one volume of medium was added and the agitation speed was increased to $160 \mathrm{rpm}$.

For transfections in 11 square-shaped glass bottles, the cells were centrifuged and resuspended at $2 \times 10^{6}$ cells $/ \mathrm{ml}$ in $200 \mathrm{ml}$ of either RPMI 1640 containing 25 mM HEPES ( $\mathrm{pH} 7.1)$ and $0.1 \% \quad(w / v)$ Pluronic F-68 (Applichem, Darmstadt, Germany) or ProCHO5 CDM with GHT. Following DNA addition, the bottles were shaken at $110 \mathrm{rpm}$ at $37^{\circ} \mathrm{C}$ in $5 \% \mathrm{CO}_{2}$ with $85 \%$ humidity with the bottle caps opened one quarter of a turn. After $4 \mathrm{~h}$, one volume of medium was added. At $24 \mathrm{~h}$ post-transfection, the bottles were shaken at $110 \mathrm{rpm}$ at $37^{\circ} \mathrm{C}$ without $\mathrm{CO}_{2}$ and humidity control. The cultures were fed upon need with glucose to $4 \mathrm{~g} / \mathrm{l}$, glutamine to $4 \mathrm{mM}$, and sodium bicarbonate to $10 \mathrm{mM}$.

For transfections in bioreactors, the cells were centrifuged and resuspended in either ProCHO5 CDM with GHT or RPMI 1640 with $25 \mathrm{mM}$ HEPES ( $\mathrm{pH} 7.1$ ) and $0.1 \%$ (w/v) Pluronic F-68 and transferred to a 31 bioreactor (Applikon, Knuellwald, The Netherlands) or a 1501 bioreactor (Bioengineering, Wald, Switzerland) containing sufficient prewarmed medium to give $2 \times 10^{6}$ cells $/ \mathrm{ml}$. Transfection was performed immediately after seeding and the cultures were stirred at $150 \mathrm{rpm}$. After $4 \mathrm{~h}$, one volume of ProCHO5 CDM with GHT was added, and the agitation speed was increased to $200 \mathrm{rpm}$. The $\mathrm{pH}$ was maintained at 7.1 using $\mathrm{NaOH}$ and $\mathrm{CO}_{2}$, and dissolved $\mathrm{O}_{2}$ was maintained at $20 \%$ by sparging air into the culture. As described above, the cultures were fed upon need with glucose, glutamine, and sodium bicarbonate.

\section{Protein analysis}

GFP expression was measured with a Cytoflour 4000 plate-reading fluorometer (PerSeptive Biosystems, Inc., Farmington, MA) after lysis of the cells by addition of Triton $\mathrm{X}-100$ to give $0.1 \%$ (Hunt et al. 1999). The IgG concentration in the culture medium was determined by sandwich ELISA as previously described (Meissner et al. 2001). For glycosylation analysis, IgG was purified by affinity chromatography using a Streamline protein A column (Amersham GE Healthcare, Switzerland). The column was equilibrated with 5 bed volumes of $50 \mathrm{mM}$ sodium phosphate ( $\mathrm{pH}$ 7.0). After sample loading, the column was washed with 10 column volumes of the same buffer. IgG was eluted with 2 bed volumes of $0.1 \mathrm{M}$ sodium citrate $(\mathrm{pH} 3.0)$ and immediately buffered with $10 \%(\mathrm{v} / \mathrm{v})$ of $1 \mathrm{M}$ Tris/ $\mathrm{HCl}$ ( $\mathrm{pH}$ 8.0). The samples were desalted and concentrated with Microcon Y-10 filters (Millipore) and then treated with peptide $N$ glycosidase F (PNGase F) (QAbio, Palm Desert, CA) according to the manufacturer's protocol. SDS-PAGE was performed with a NuPAGE 4$12 \%$ polyacrylamide gradient gel (Invitrogen) and stained with Coomassie Blue.

\section{Results}

Determination of transfection parameters in 12-well plates

The feasibility of transfecting directly in ProCHO5 CDM medium was initially investigated in 12-well plates. In these experiments three parameters, the DNA:PEI ratio, the cell density, and the age of the culture at the time of transfection were varied. To determine the 
Table 1 Effect of PEI:DNA ratio on transient gene expression

\begin{tabular}{lcl}
\hline DNA:PEI ratio $(\mathrm{w} / \mathrm{w})^{\mathrm{a}}$ & ${\text { GFP }(\mathrm{RFU})^{\mathrm{b}}}$ & $\mathrm{IgG}(\mathrm{mg} / \mathrm{l})^{\mathrm{c}}$ \\
\hline $1: 2 \mathrm{R}$ & $2550 \pm 180$ & $5.3 \pm 0.7$ \\
$1: 2$ & $860 \pm 260$ & $1.7 \pm 0.9$ \\
$1: 3$ & $1690 \pm 290$ & $4.5 \pm 0.2$ \\
$1: 4$ & $3000 \pm 390$ & $6.9 \pm 0.5$ \\
$1: 5$ & $2850 \pm 140$ & $6.9 \pm 0.2$ \\
$1: 6$ & $2750 \pm 150$ & $5.0 \pm 0.1$ \\
\hline
\end{tabular}

${ }^{\mathrm{a} C e l l s}$ were seeded at $2 \times 10^{6}$ cells $/ \mathrm{ml}$ in either ProCHO5 CDM or RPMI $1640(\mathrm{R})$ and transfected with pEAK8LH39, pEAK8-LH41, and pEGFP-N1 at various DNA: PEI ratios as indicated

b The relative fluorescence units (RFU) were determined by fluorometry after cell lysis at $3 \mathrm{~d}$ post-transfection. The average of three transfections is shown

c IgG concentration in cell culture medium was measured by ELISA at $3 \mathrm{~d}$ post-transfection. The average of three transfections is shown

optimum DNA:PEI ratio, the cells in either ProCHO5 CDM or RPMI 1640 were transfected with a mixture of pEAK-LH41, pEAK-LH39, and pEGFP-N1. The final DNA concentration was kept constant at $2.5 \mu \mathrm{g} / \mathrm{ml}$, and the DNA:PEI ratio was varied from 1:2 to $1: 6(\mathrm{w} / \mathrm{w})$. For the transfections in ProCHO5 CDM, DNA:PEI ratios of $1: 4$ and $1: 5(\mathrm{w} / \mathrm{w})$ resulted in the highest levels of GFP and antibody expression (Table 1). By comparison the highest protein yields for the transfections in RPMI 1640 were observed at a DNA:PEI ratio of 1:2 (w/w) (Table 1 ; only the results from the transfection at a DNA:PEI ratio of 1:2 are shown). Slightly higher levels of both GFP and antibody were observed for the transfections in ProCHO5 CDM as compared to those in RPMI 1640 (Table 1).

Using a DNA:PEI ratio of 1:4 (w/w), the effect of cell density on transient recombinant protein expression in ProCHO5 CDM was investigated. Cells at either 1 or $2 \times 10^{6}$ cells $/ \mathrm{ml}$ were transfected as described above. At $3 \mathrm{~d}$ post-transfection, the highest level of antibody accumulation $(4.9 \pm 0.6 \mathrm{mg} / \mathrm{l})$ was observed at a density of $2 \times 10^{6}$ cells $/ \mathrm{ml}$. Subsequent experiments in other cultivation systems were therefore performed at this cell density.

To determine the effect of culture age on transient gene expression, the cells were cultivated in ProCHO5 $\mathrm{CDM}$ for $1-7 \mathrm{~d}$ prior to transfection. On the day of transfection, the density of each culture was approximately $3 \times 10^{6}$ cells $/ \mathrm{ml}$. The cells from each culture were either centrifuged and resuspended in fresh ProCHO5 CDM or maintained in conditioned medium. In either case, the cells were seeded at $2 \times 10^{6}$ cells $/ \mathrm{ml}$ in 12 -well plates and transfected with a mixture of $10 \%$ pEAK 8 and $90 \%$ pEGFPN-1 at various DNA:PEI ratios. The level of GFP expression at $3 \mathrm{~d}$ post-transfection was dependent on the age of the culture at the time of transfection (Fig. 1). With an increase in cultivation time, a decrease in GFP expression was observed. In addition, the transfer of cells into fresh medium at the time of transfection was necessary for efficient PEI-mediated gene transfer; little GFP expression was observed following the transfection of the one-day old culture $(N-1)$ in conditioned medium (Fig. 1). Furthermore, the transfection of four- and seven-day old cultures in conditioned medium did not result in significant levels of GFP expression using DNA:PEI ratios up to 1:9 (w/w) (data not shown). It was concluded that for PEI-mediated transfection in ProCHO5 CDM, it was preferable to use cells that were maintained for only $1 \mathrm{~d}$ in this medium

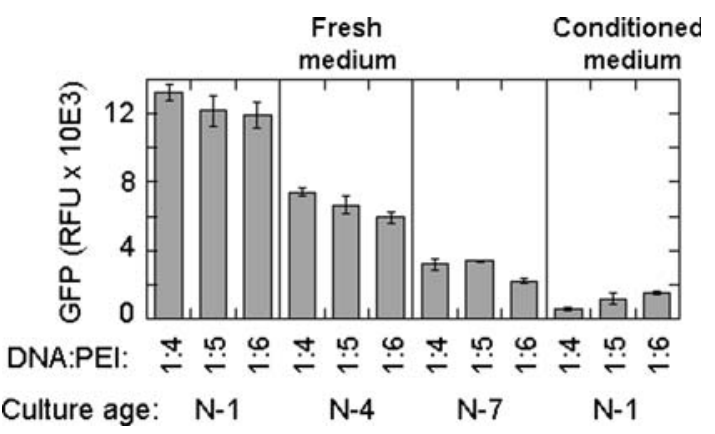

Fig. 1 Effect of culture age on transient gene expression. CHO DG44 cells grown in ProCHO5 CDM for either one $(N-1)$, four $(N-4)$, or seven $(N-7)$ days were either centrifuged and resuspended in fresh ProCHO5 CDM ximmediately before transfection or were transfected directly in the conditioned medium. The cells were seeded in 12-well plates at $2 \times 10^{6}$ cells $/ \mathrm{ml}$ and transfected with a mixture of $90 \%$ pEAK 8 and $10 \%$ pEGFPN-1 at various DNA:PEI ratios. The cells were diluted with one volume of ProCHO5 CDM at $4 \mathrm{~h}$ post-transfection. GFP expression was measured at $3 \mathrm{~d}$ post-transfection. The average of three transfections is shown 
before passage to fresh medium immediately before transfection.

Transfections in 50-ml ventilated centrifuge tubes

Cells in $2.5 \mathrm{ml}$ of ProCHO5 CDM were transfected at a DNA:PEI ratio of 1:4 (w/w). The cultures were either fed with glucose (to $4 \mathrm{~g} / \mathrm{l}$ ) and glutamine (to $4 \mathrm{mM}$ ) upon need or left unfed. By $5 \mathrm{~d}$ post-transfection, the level of antibody was similar for both fed and unfed cultures (Fig. 2A). However, the biomass of the fed culture was higher than that of the unfed culture at 5-7 d post-transfection (Fig. 2B). These results demonstrated that the feeding of glucose and glutamine is not necessary following transfection in this
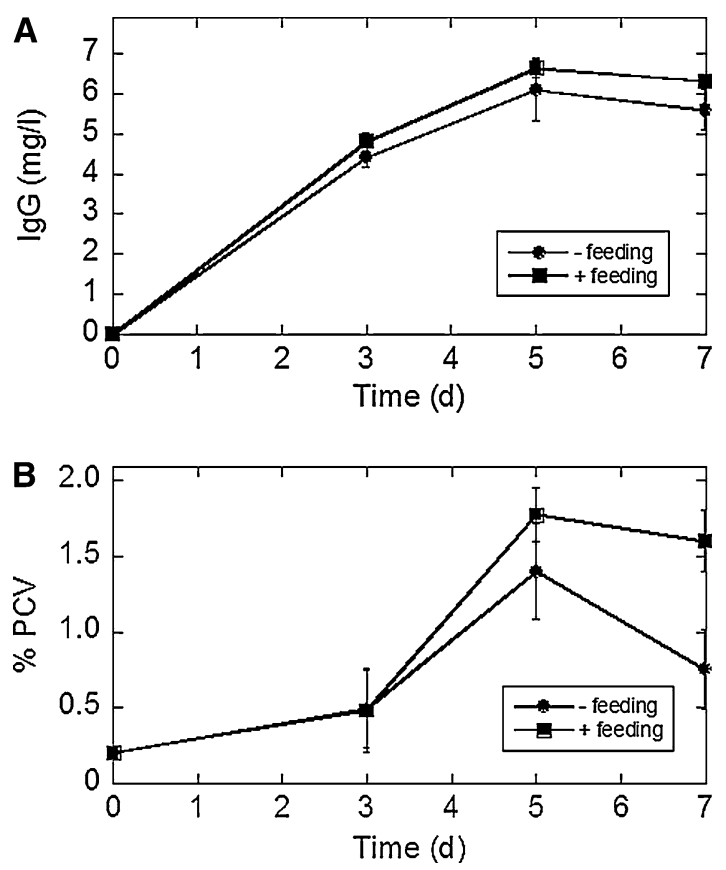

Fig. 2 Transfection in $50 \mathrm{ml}$ centrifuge tubes. CHO DG44 cells were seeded in duplicate in $50 \mathrm{ml}$ tubes in $2.5 \mathrm{ml}$ of ProCHO5 CDM and transfected with a mixture of pEAK8-LH39, pEAK8-LH41, and pEGFP-N1 at a DNA:PEI ratio of $1: 4(\mathrm{w} / \mathrm{w})$. At $4 \mathrm{~h}$ post-transfection, one volume of ProCHO5 CDM was added to each tube. The cultures were either maintained without feeding (no feeding) or were fed upon need with glutamine and glucose (feeding). At the times indicated the antibody concentration in the culture medium was determined by ELISA (A) and the packed cell volume (\% PCV) was determined with a mini-PCV tube $(\mathbf{B})$ vessel if the cultures are only maintained for up to $7 \mathrm{~d}$.

Transfections in 1-liter square-shaped bottles

The cells were transfected at a DNA:PEI ratio of either 1:2 or 1:4 (w/w) in RPMI 1640 or ProCHO5 CDM, respectively. At $5 \mathrm{~d}$ post-transfection, the IgG yield for the transfection in ProCHO5 CDM was almost twice that for the one in RPMI 1640 (Fig. 3). The higher antibody level in ProCHO5 $\mathrm{CDM}$ was not due to a greater accumulation of biomass since there was not a significant difference in the \% PCV between the two cultures (data not shown). The approximate specific productivities for the transfections in ProCHO5 CDM and RPMI 1640 were 1.3 and $0.7 \mathrm{pg} /$ cell d, respectively. Similar results to those shown in Fig. 3 were observed for transfections in $250-\mathrm{ml}$ square-shaped glass bottles (data not shown). Subsequent to this experiment the transfection in square-shaped bottles was further simplified by demonstrating that incubation in the presence of $\mathrm{CO}_{2}$ was not necessary as long as the bottle caps were tightly closed for $24 \mathrm{~h}$ post-transfection and then opened about one quarter of a turn for the remainder of the cultivation period (data not shown).

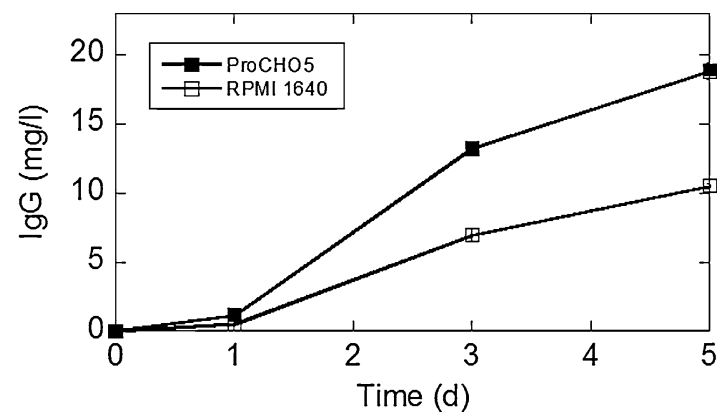

Fig. 3 Transfection in 11 square-shaped bottles. $\mathrm{CHO}$ DG44 cells were seeded in duplicate in either ProCHO5 CDM or RPMI 1640 in 11 square bottles. The cells were transfected with a mixture of pEAK8-LH39, pEAK8-41, and pEGFP-N1 at a DNA:PEI ratio of either 1:4 (w/w) in ProCHO5 CDM or 1:2 (w/w) in RPMI 1640. At the times indicated the antibody concentration in the medium was determined by ELISA 
Transfections in bioreactors

The cells were seeded in 3-1 bioreactors at $2 \times 10^{6}$ cells $/ \mathrm{ml}$ in $500 \mathrm{ml}$ of either ProCHO5 CDM or RPMI 1640 as described in the previous section. By $7 \mathrm{~d}$ post-transfection, the antibody yield reached $18 \mathrm{mg} / \mathrm{l}$ for the transfection in ProCHO5 CDM and $12 \mathrm{mg} / \mathrm{l}$ for that in RPMI 1640 (Fig. 4A). The biomass for the two cultures was about the same until day 4 (Fig. 4B). For both cultures the cell viability was above $90 \%$ through day 6 post-transfection (Fig. 4C). Surprisingly, there was little increase in $\mathrm{IgG}$ accumulation after day 5 for either culture despite the fact that the biomass increased from $0.9 \%$ to $1.2 \%$ PCV for the transfection in ProCHO5 CDM during this period (Fig. 4C). Despite the difference in antibody yield for the two cultures, the specific productivities, $0.9 \mathrm{pg} / \mathrm{cell} \mathrm{d}$ in ProCHO5 CDM and $0.8 \mathrm{pg} /$ cell $\mathrm{d}$ in RPMI 1640, were about the same.

For the transfection in a 1501 bioreactor, the cells were seeded in 401 of ProCHO5 CDM at $2 \times 10^{6}$ cells $/ \mathrm{ml}$, and the culture was transfected at a DNA:PEI ratio of 1:4 (w/w). The antibody yield $(22 \mathrm{mg} / \mathrm{l})$ was similar to that observed in $3 \mathrm{l}$ bioreactors (Fig. 5A). The cell density reached a maximum of $4 \times 10^{6}$ cells $/ \mathrm{ml}$ at $3-4$ d post-transfection and then declined (Fig. 5B). In contrast to the results in 31 bioreactors, the viability of the culture decreased rapidly after day 4 and eventually fell to $50 \%$ by day 6 (Fig. 5B). The specific productivity was $1 \mathrm{pg} /$ cell.d.

Transiently produced anti-Rhesus D IgG from the 1501 bioreactor and the same antibody expressed from a recombinant $\mathrm{CHO}$ cell line (CHO AMW) (MJ De Jesus and FM Wurm, unpublished data) were purified by protein A-based affinity chromatography. These samples plus IgG from a commercial source (Jackson ImmunoReasearch) were deglycosylated with PNGase F, an enzyme that catalyzes the release of N-linked oligosaccharides from proteins. The heavy chain of the anti-Rhesus D IgG, regardless if it was expressed transiently or stably from $\mathrm{CHO}$ cells, had about $3 \mathrm{kDa}$ of glycosylation judging from the band shift of the heavy chain with and without PNGase F treatment (Fig. 6). As a comparison, the heavy chain of the unrelated
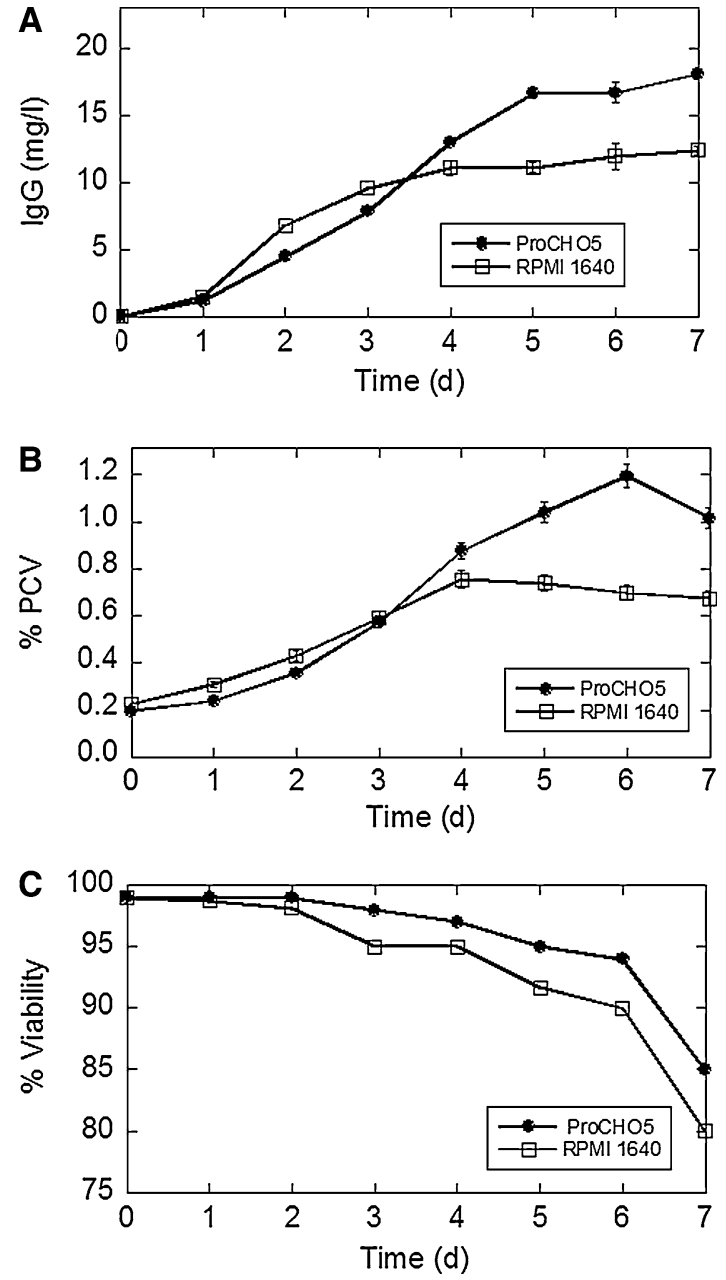

Fig. 4 Transfection in 31 bioreactors. CHO DG44 cells were seeded in duplicate in $500 \mathrm{ml}$ of either ProCHO5 CDM or RPMI 1640 in 31 bioreactors. The cultures were transfected with a mixture of pEAK8-LH39, pEAK8LH41, and pEGFP-N1 at a DNA:PEI ratio of either 1:4 (w/w) in ProCHO5 CDM or 1:2 (w/w) in RPMI 1640. The cultures were diluted with one volume of ProCHO5 CDM after $4 \mathrm{~h}$. At the times indicated the antibody concentration in the medium was measured by ELISA (A), the packed cell volume (\% PCV) was determined with a miniPCV tube (B), and cell viability was determined with the Trypan Blue exclusion method $(\mathbf{C})$

commercial IgG had about $2 \mathrm{kDa}$ of glycosylation (Fig. 6).

\section{Discussion}

Transient gene expression in mammalian cells is a promising approach to the generation of 

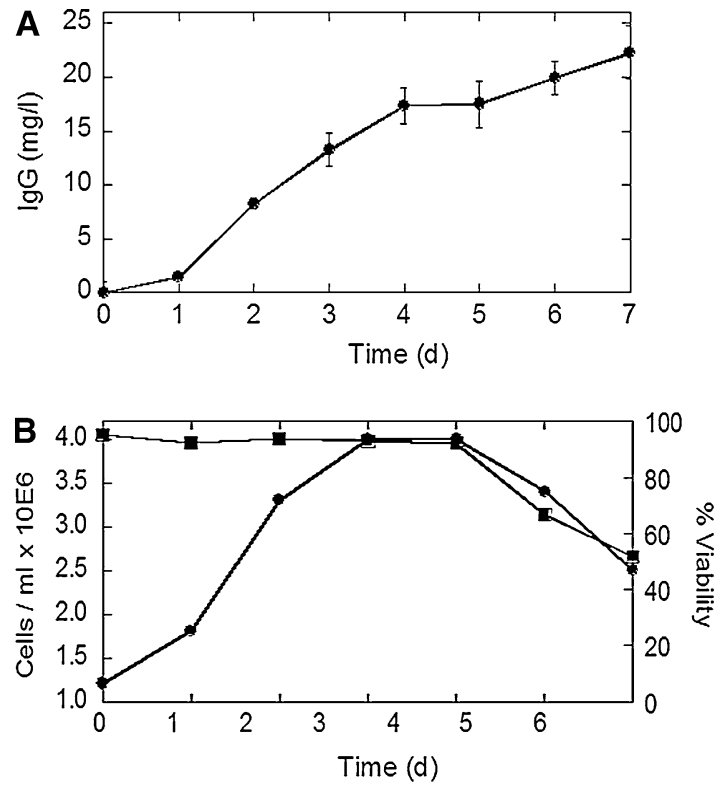

Fig. 5 Transfection in a 150-1 bioreactor. CHO DG44 cells were seeded in 401 of ProCHO5 CDM. The cells were transfected with a mixture of pEAK8-LH39, pEAK8LH41, and pEGFP-N1 at a DNA:PEI ratio of 1:4 (w/w) and then diluted with one volume of ProCHO5 CDM at $4 \mathrm{~h}$ post-transfection. At the times indicated the antibody concentration was determined by ELISA (A) and the viable cell number and the percent viability were determined by manual counting with the Trypan blue exclusion method (B)

milligram to gram quantities of recombinant proteins. Here we describe a transient gene expression method that is applicable to both instrumented and non-instrumented cultivation systems at a broad range of scales. We have previously described PEI-mediated transfection of suspension-adapted CHO DG44 cells in serumfree minimal medium (RPMI 1640) in which antibody yields in the range of $2-6 \mathrm{mg} / \mathrm{l}$ were achieved at volumes up to 131 (Derouazi et al. 2004). For those experiments, ProCHO5 CDM, a medium formulated for high-density growth of $\mathrm{CHO}$ cells in the absence of animal-derived components, was used for cell cultivation but the transfection itself was performed in RPMI 1640 with a dilution in ProCHO5. Here the latter was used for the entire bioprocess. When compared directly, recombinant protein expression was higher for transfections in ProCHO5 CDM than in RPMI 1640. The improved method yielded similar levels of recombinant antibody

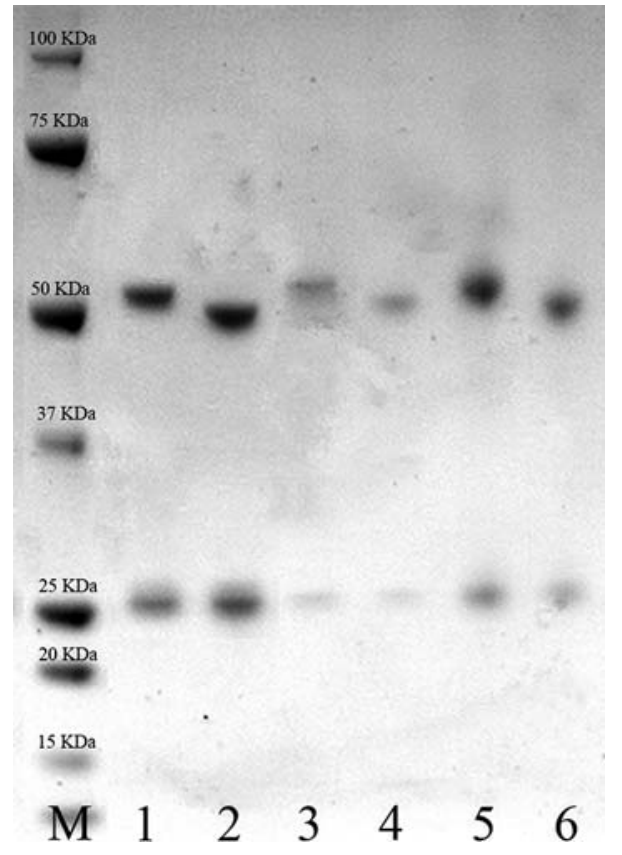

Fig. 6 SDS-PAGE analysis of IgG glycosylation. AntiRhesus D IgG from the transient transfection in the 150-1 bioreactor (lanes 1 and 2) and from CHO AMW (lanes 3 and 4) were affinity purified. These samples and a commercial IgG (lanes 5 and 6) were deglycosylated with PNGase F. Protein samples before (lanes 1, 3, and 5) and after treatment with PNGase F (lanes 2, 4, and 6) were electrophoresed on a 4-12\% polyacrylamide gradient gel. The molecular weight marker is shown in the left lane

in both standard stirred bioreactors and agitated non-instrumented cultivation systems including $50 \mathrm{ml}$ ventilated centrifuge tubes and 11 squareshaped glass bottles.

The agitated square-shaped bottle is an attractive option for both cell cultivation and transient transfection. For routine cultivation of $\mathrm{CHO}$ cells, densities of $5 \times 10^{6}$ cells $/ \mathrm{ml}$ are typically achieved (Muller et al. 2005). The transfections in 11 square bottles described here yielded about $20 \mathrm{mg} / \mathrm{l}$ of antibody as compared to yields of 18 and $22 \mathrm{mg} / \mathrm{l}$ in 3- and $150 \mathrm{l}$ bioreactors, respectively. Importantly, this simple cultivation system does not require instrumented control of the $\mathrm{O}_{2}$, $\mathrm{CO}_{2}$, and $\mathrm{pH}$ levels. Thus, agitated square-shaped bottles may eventually become an alternative to instrumented bioreactors for transient gene expression in mammalian cells. Although only results from transfections in 11 bottles are provided here, we have also cultivated and 
transfected $\mathrm{CHO}$ cells in both smaller and larger square- and round-shaped containers of either glass or plastic (M Stettler and FM Wurm, unpublished data).

The $50 \mathrm{ml}$ ventilated centrifuge tubes described here provide a convenient cultivation system for high-throughput, small-scale transfections. They offer advantages over agitated multiwell plates in having a very low evaporation rate under humidified cultivation conditions and a working volume up to $20 \mathrm{ml}$ per tube. They also support the routine cultivation of $\mathrm{CHO}$ cells to densities of $8-10 \times 10^{6}$ cells/ml (M Stettler and FM Wurm, unpublished data) and are suitable for the multiparameter screening of bioprocess conditions (De Jesus et al. 2004). Importantly, the transient recombinant protein yields in these tubes were similar to those achieved in standard stirred tank bioreactors, demonstrating the scalability of processes optimized in this disposable vessel.

The highest transgene expression levels in ProCHO5 CDM and RPMI 1640 were achieved by transfection at DNA:PEI ratios of 1:4 (w/w) and 1:2 (w/w), respectively. One possible explanation for this difference is the presence of one or more components in ProCHO5 CDM which interact with PEI. If PEI has a higher affinity for a component(s) in the medium than it does for DNA, then the active transfection complex may be disrupted, resulting in a decrease in the efficiency of gene delivery (Godbey et al. 1999). Indeed, it has been shown that PEI forms a precipitate with an unknown component(s) in ProCHO5 CDM (M Bertschinger and FM Wurm, unpublished data). Thus, transfection in this medium may require addition PEI to prevent disassembly of the preformed PEI/DNA complexes.

The transient antibody yields achieved here are among the highest reported for $\mathrm{CHO}$ cells. Certainly, the $22 \mathrm{mg}$ antibody/l produced in an 801 transfection is the highest reported for a multiliter process. These results demonstrate the feasibility of producing gram amounts of recombinant antibody by transient transfection of $\mathrm{CHO}$ cells. By comparison, recombinant $\mathrm{CHO}$ cell lines may yield as much as $4 \mathrm{~g}$ antibody/l with specific productivities of $50 \mathrm{pg} / \mathrm{cell} \mathrm{d}$ or more (Wurm
2004). These differences in recombinant protein yield suggest that further improvements in transient gene expression in mammalian cells are possible. Optimization of media, gene delivery methods, cultivation systems, and expression vectors are expected to close this gap, making transient gene expression an even more attractive option for the rapid production of recombinant proteins.

Acknowledgements The authors thank Rachel Flaction, Ilda Muller, and Elisabeth Derow for technical assistance and Dr. Maria De Jesus for cell line AMW. Financial support for this work was provided by the Swiss CTI Innovation Promotion Agency.

\section{References}

Baldi L, Muller N, Picasso S, Jacquet R, Girard P, Thanh HP, Derow E, Wurm FM (2005) Transient gene expression in suspension HEK-293 cells: Application to large-scale protein production. Biotechnol Prog 21:148-153

Boussif O, Lezoualc'h F, Zanta MA, Mergny MD, Scherman D, Demeneix B, Behr JP (1995) A versatile vector for gene and oligonucleotide transfer into cells in culture and in vivo: polyethylenimine. Proc Natl Acad Sci USA 92:7297-7301

De Jesus MJ, Girard P, Bourgeois M, Baumgartner G, Jacko B, Amstutz H, Wurm FM (2004) TubeSpin satellites: a fast track approach for process development with animal cells using shaking technology. Biochem Eng J 17:217-223

Derouazi M, Girard P, Van Tilborgh F, Iglesias K, Muller N, Bertschinger M, Wurm FM (2004) Serum-free large-scale transient transfection of $\mathrm{CHO}$ cells. Biotechnol Bioeng 87:537-545

Galbraith DJ, Tait AS, Racher AJ, Birch JR, James DC (2006) Control of culture environment for improved polyethylenimine-mediated transient production of recombinant monoclonal antibodies by $\mathrm{CHO}$ cells. Biotechnol Prog 22:753-762

Girard P, Derouazi M, Baumgartner G, Bourgeois M, Jordan M, Jacko B, Wurm FM (2002) 100-liter transient transfection. Cytotechnology 38:15-21

Girard P, Jordan M, Tsao M, Wurm FM (2001) Small-scale bioreactor system for process development and optimization. Biochem Eng J 7:117-119

Godbey WT, Wu KK, Hirasaki GJ, Mikos AG (1999) Improved packing of poly(ethylenimine)/DNA complexes increases transfection efficiency. Gene Ther 6:1380-1388

Hunt L, Jordan M, De Jesus M, Wurm FM (1999) GFPexpressing mammalian cells for fast, sensitive, noninvasive cell growth assesment in a kinetic mode. Biotechnol Bioeng 65:201-205 
Jordan M, Schallhorn A, Wurm FM (1996) Transfecting mammalian cells: optimization of critical parameters affecting calcium-phosphate precipitate formation. Nucleic Acids Res 24:596-601

Meissner P, Pick H, Kulangara A, Chatellard P, Friedrich K, Wurm FM (2001) Transient gene expression: Recombinant protein production with suspensionadapted HEK293-EBNA cells. Biotechnol Bioeng 75:197-203

Muller N, Girard P, Hacker DL, Jordan M, Wurm FM (2005) Orbital shaker technology for the cultivation of mammalian cells in suspension. Biotechnol Bioeng 89:400-406

Pham PL, Perret S, Doan HC, Cass B, St-Laurent G, Kamen A, Durocher Y (2003) Large-scale transient transfection of serum-free suspension-growing HEK293 EBNA1 cells: peptone additives improve cell growth and transfection efficiency. Biotechnol Bioeng 84:332342

Pham PL, Pettet S, Cass B, Carpentier E, St-Laurent G, Bisson L, Kamen A, Durocher Y (2005) Transient gene expression in HEK293 cells: peptone addition posttransfection improves recombinant protein synthesis. Biotechnol Bioeng 90:332-344

Pick HM, Meissner M, Preuss AK, Tromba P, Vogel H, Wurm FM (2002) Balancing GFP reporter plasmid quantity in large-scale transient transfections for recombinant anti-human Rhesus-D IgG1 synthesis. Biotechnol Bioeng 79:595-601

Rosser MP, Xia W, Hartsell S, McCaman M, Zhu Y, Wang S, Harvey S, Bringman P, Cobb RR (2005) Transient transfection of CHO-K1-S using serum-free medium in suspension: a rapid mammalian protein expression system. Protein Expr Purif 40:237-243

Schlaeger EJ, Christensen K (1999) Transient gene expression in mammalian cells grown in serum- free suspension culture. Cytotechnology 30:71-83

Schlaeger EJ, Kitas EA, Dorn A (2003) SEAP expression in transiently transfected mammalian cells grown in serum-free suspension culture. Cytotechnology 42:47-55

Stettler M, Jaccard N, Hacker DL, De Jesus M, Wurm FM, Jordan M (2006) New disposable tubes for rapid and precise biomass assessment for suspension cultures of mammalian cells. Biotechnol Bioeng 95:1228-1233

Tait AS, Brown CJ, Galbraith DJ, Hines MJ, Hoare M, Birch JR, James DC (2004) Transient production of recombinant proteins by Chinese hamster ovary cells using polyethyleneimine/DNA complexes in combination with microtubule disrupting anti-mitotic agents. Biotechnol Bioeng 88:707-721

Wurm FM (2004) Production of recombinant protein therapeutics in cultivated mammalian cells. Nat Biotechnol 22:1393-1398 